\title{
QUESTÕES METODOLÓGICAS NA PESQUISA EM EDUCAÇÃO AMBIENTAL: NECESSIDADES E DESAFIOS
}

\author{
Marília Freitas de Campos Tozoni-Reis ${ }^{1}$ \\ Clarice Sumi Kavasaki ${ }^{2}$
}

\begin{abstract}
Resumo
Este artigo apresenta uma síntese das discussões sobre metodologia de pesquisa em educação ambiental realizadas durante o VIII Encontro de Pesquisa em Educação Ambiental - EPEA, em julho de 2015 na cidade do Rio de Janeiro - RJ. Elas foram realizadas nos dois encontros do Grupo de Discussão de Pesquisa em Educação Ambiental e Questões Metodológicas, um espaço criado pela organização dos EPEAs para o aprofundamento de temas relevantes para a Pesquisa em Educação Ambiental, que vem se consolidando como um espaço importante para esses aprofundamentos e para indicar caminhos para a atividade científica de pesquisa neste campo da educação no Brasil. O GDP que vivenciou essas discussões foi coordenado pelas autoras.
\end{abstract}

Palavras-chave: Pesquisa em educação ambiental. Metodologia de pesquisa. Temas relevantes.

\section{METHODOLOGICAL ISSUES IN ENVIRONMENTAL EDUCATION RESEARCH: NEEDS AND CHALLENGES}

\begin{abstract}
This article presents a synthesis of the discussions on environmental education research methodology held during the VIII Encontro de Pesquisa em Educação Ambiental (VIII Environmental Education Research Conference) - EPEA, in the city of Rio de Janeiro - RJ in July, 2015. They were conducted during two meetings of Grupo de Discussão de Pesquisa em Educação Ambiental e Questões Metodológicas (Group for Discussion on Environmental Education Research and Methodological Issues) - GDP, an opening provided by the organization committees of EPEAs for furthering the knowledge on relevant topics in Environmental Education Research which has been consolidated as an important opportunity to develop such knowledge and indicate new avenues for scientific research activity in this education field in Brazil. The GDP which experienced such discussions was coordinated by the authors.
\end{abstract}

Keywords: Environmental education research. Research methodology. Relevant topics.

\section{CUESTIONES METODOLÓGICAS EN LA INVESTIGACIÓN EN EDUCACIÓN AMBIENTAL: NECESIDADES Y DESAFÍOS}

\section{Resumen}

En este artículo se presenta un resumen de los debates sobre metodología de la investigación en educación ambiental realizadas durante el VIII Encuentro de Investigación en Educación Ambiental - EPEA, en julio de 2015 en la ciudad de Río de Janeiro - RJ. Ellos se llevaron a cabo en las dos reuniones del Grupo de Investigación de Debate sobre Educación Ambiental y las Cuestiones Metodológicas, un espacio creado por la organización de los EPEAs para la

\footnotetext{
${ }^{1}$ Professora Dra do IB-UNESP-Botucatu
}

${ }^{2}$ Professor Doutor da FFCLRP-USP. 
profundización de temas relevantes para la Investigación en Educación Ambiental, que se ha consolidado como un espacio importante para estas penetraciones y para indicar caminos para la actividad de investigación científica en el campo de la educación en Brasil. El GDP que vivenció estas discusiones fue coordinado por las autoras.

Palabras-clave: Investigación en Educación Ambiental. Metodología de Pesquisa. Temas relevantes.

\section{Introdução}

Os pesquisadores em educação ambiental, atuantes no Brasil, tem participado dos Encontros de Pesquisa em Educação Ambiental - EPEAs - encontrando-se em muitos de seus espaços acadêmicos, inclusive nos Grupos de Discussão de Pesquisa (GDPs), atividade importante que vem se consolidando nesses eventos, contribuindo também para a consolidação da educação ambiental como um campo de pesquisa cada vez mais pujante. Os GDPs concretizam-se nos EPEAs através de sessões para discussão e aprofundamento dos diferentes aspectos das atividades de pesquisa em educação ambiental, mas têm, também, oportunizado o encontro dos pesquisadores que tratam de aspectos comuns em seus trabalhos, constituindose, portanto, num espaço de discussão das tendências, das dificuldades e dos avanços teóricos e metodológicos da pesquisa em educação ambiental.

São duas as sessões dos GDPs em cada EPEA, com duas horas de duração, e são coordenadas por pesquisadores convidados, com experiência nos temas em discussão. Nunca é demais insistir, como já indicado em trabalhos anteriores que tratam desse tema (TOZONI-REIS; SOUZA, 2014, entre outros) que a orientação geral da Comissão dos EPEAs é de que a inscrição nos GDPs deve levar em conta o trabalho do pesquisador, isto é, não é o pesquisador individualmente que está inscrito nesses Grupos, mas o pesquisador com o trabalho que apresentará no evento. O que se espera, aqui, é reunir aqueles que se dedicam aos mesmos temas - não apenas os que se interessam por ele - para que os GDPs tenham um histórico de discussão acumulada desses temas, de forma que possa contribuir mais aprofundadamente para os avanços - teórico e metodológico - da pesquisa em educação ambiental.

Esse tem sido o principal desafio na organização e coordenação dos GDPs. A Comissão Organizadora, por um lado, vêm empreendendo esforços para que os objetivos dos GDPs estejam mais claros no processo de divulgação e inscrição dos EPEAs, enquanto que os seus coordenadores participantes se esforçam para relacionar os trabalhos vinculados a cada GDP aos temas em análise. Se o principal objetivo dessa atividade nesse evento em que se dedica ao estudo e discussão da Pesquisa em educação ambiental é garantir nos Grupos um espaço de socialização, aprofundamento e ampliação das discussões sobre temas relevantes, a cultura de participação em eventos que o mundo acadêmico produz, que tem levado os participantes a se dispersar em um número cada vez maior de atividades e apresentação de trabalhos, tem prejudicado a continuidade das discussões ao longo das edições dos EPEAs. Nossa expectativa é que os pesquisadores participantes dos eventos se mantenham vinculados aos GDPs, para consolidá-los como um espaço permanente de discussões, acumulando conhecimentos e discussões sobre esses diferentes aspectos da Pesquisa em Educação Ambiental.

Como parte das tarefas de Coordenação dos GDPs apresentamos, neste artigo, a organização e o funcionamento do Grupo de Discussão de Pesquisa em EA e Questões Metodológicas, que realizou-se no VIII EPEA, em 2015, na cidade do Rio de Janeiro. 


\section{O GDP de Questões Metodológicas da Pesquisa em Educação Ambiental no VIII EPEA}

Uma das coisas que mais nos chamaram atenção no EPEA de 2015 foi o número reduzido de participantes nas discussões do GDP de Questões Metodológicas. Considerando as duas sessões, o número de participantes foi de apenas oito pesquisadores, excluindo-se, aqui, as duas coordenadoras. Sabemos que as questões metodológicas da pesquisa são, em geral, menos atraentes para os participantes dos eventos acadêmicos do que outros temas. No entanto, se considerarmos que os EPEAs são eventos dedicados especialmente à pesquisa, e que o campo da educação ambiental é constituído por pesquisadores que migram de muitas e variadas áreas do conhecimento para a área da Educação, essencialmente uma ciência inserida nas Ciências Humanas e Sociais, nossa expectativa de que esse tema seja um assunto de preocupação dos pesquisadores não foi confirmada pela procura dos participantes a esse GDP, neste VIII EPEA. Também nos chamou atenção o fato de que em 2013 - com as mesmas características aqui levantadas sobre os participantes - houve uma participação bem mais efetiva.

Apesar disso, observamos que desses oito participantes, três já tinham participado deste mesmo GDP na edição anterior, o que é um indicador importante para nossas expectativas de continuidade das discussões.

Os trabalhos foram organizados de forma que os participantes do Grupo fossem orientados por algumas questões, evitando-se, assim, discussões dispersas e circulares. As questões colocadas foram:

1) Por que escolheu este GDP?

2) Quais são as suas expectativas em relação a este GDP?

3) Quais são os aspectos/questões metodológicas de sua pesquisa?

4) Quais são os aspectos/questões metodológicas que gostaria de discutir?

5) Como avalia este GDP?

As duas primeiras questões foram discutidas conjuntamente, já que as expectativas de cada um dos participantes se misturavam com as razões pelas quais escolheram este GDP. As discussões giraram em torno dos seguintes aspectos: a busca por um caminho metodológico; o interesse por uma técnica/método específico; a necessidade de conhecer e compartilhar os diferentes aportes teóricos e metodológicos da pesquisa em EA; por entender a metodologia como espinha dorsal da pesquisa e os caminhos metodológicos como desafio para o pesquisador; para dar continuidade às discussões em torno das Questões Metodológicas da Pesquisa em EA, iniciadas na edição anterior do EPEA.

Quanto aos aspectos/questões metodológicas das pesquisas dos participantes, é importante observar que tivemos um único trabalho inscrito no GDP que tratasse, em seu conteúdo, de Questões Metodológicas, um estudo sobre a análise crítica do discurso como caminho teóricometodológico na compreensão e no enfrentamento da questão ambiental (VENTURA; FREIRE, 2015). A partir da premissa de que a questão ambiental transforma as práticas discursivas de uma sociedade ou instituição, o estudo buscou compreender essas práticas discursivas, tendo a análise crítica do discurso como marco teórico e metodológico. Interessante observar, também, que o estudo vincula a escolha metodológica - a análise do discurso - com o referencial teórico - a educação ambiental crítica, o que é uma das principais dificuldades identificadas nas questões metodológicas da pesquisa em educação ambiental, discutida no GDP, nesta e em outras edições dos EPEAs. Esse vínculo fica muito claro quando o artigo propõe o enfrentamento das questões ambientais por meio de uma educação ambiental crítica, uma nova ordem social e novas formas de uso da linguagem.

Embora apenas um trabalho se relacionasse diretamente com as questões metodológicas dentre os inscritos no GDP, os demais participantes apresentaram para o Grupo esse aspecto 
de seus trabalhos. Nessas apresentações, destacaram-se alguns aspectos metodológicos como a abordagem qualitativa da pesquisa, a modalidade de pesquisa de campo, as entrevistas como técnicas de pesquisa e o materialismo histórico dialético como referencial teórico e metodológico. Também, apareceu a "metodologia de Quintas" (sic). As discussões sobre iniciais do Grupo apontaram, ainda e mais uma vez - para o fato de que, por ser um campo em construção, a educação ambiental traz aportes de diferentes disciplinas e diferentes perspectivas teórico-metodológicas.

Quanto aos aspectos/questões metodológicas que gostariam de discutir, surgiram no Grupo algumas dúvidas que levaram à identificar a necessidade de maior aprofundamento em torno dos mesmos temas que evidenciamos como presentes nas pesquisas dos participantes do Grupo: diferentes formatos de pesquisa (ensaio teórico, pesquisa empírica, pesquisa de campo); fundamentos teórico-metodológicos da análise crítica do discurso, da Metodologia de Quintas, do Materialismo Histórico Dialético, das pesquisas do Estado da Arte e dos estudos quanti-qualitativos.

Com essas preocupações iniciais, o Grupo chegou ao segundo dia de discussões com o objetivo de destacar para o debate algumas dessas questões. Os participantes elegeram como primeira questão aquela que nos parece um problema metodológico presente nos estudos e pesquisas em educação ambiental: Qual é o objeto de estudo da Pesquisa em EA? As discussões apontaram, então, para um objeto comum em nossos estudos e pesquisas: o fenômeno educativo. Essa foi uma das discussões mais produtivas e interessantes do Grupo.

A segunda questão, abordada no segundo dia de reuniões do GDP, está diretamente relacionada ao tema que temos buscado priorizar em nossos estudos e discussões sobre as questões metodológicas na pesquisa em educação ambiental: a necessidade de garantir as relações entre a metodologia de pesquisa e o referencial teórico, isto é, não podemos trabalhar com as formas de buscar interpretar o fenômeno educativo socioambiental sem que relacionemos essas formas com nossas escolhas teóricas. Nesse sentido, o Grupo definiu para discussão a segunda questão: O que é o materialismo histórico dialético: metodologia ou teoria? Essa discussão, embora não - e nunca - esgotada, seria suficiente para mobilizar toda a discussão do GDP, mas conseguimos avançar no sentido de seu esclarecimento. Neste texto, dedicamos um item especial para essa abordagem.

Os participantes do Grupo levantaram, ainda, outros questionamentos acerca das relações entre forma e conteúdo nas pesquisas em educação ambiental, elegendo para análise uma outra questão: O que são estudos do tipo estado da arte? São metapesquisas? Também, pela sua complexidade, tratamos esse tema num item especial neste artigo.

Com referência a algumas modalidades de pesquisa em educação ambiental, os participantes do GDP indicaram a necessidade de esclarecimentos sobre os estudos quantiqualitativos. Essa necessidade foi sentida pois, segundo as discussões, o fato de termos na educação ambiental pesquisadores de muitas e variadas áreas do conhecimento, com diferentes e variadas concepções sobre o que é ciência e o que é pesquisa, somada ao fato de que nas ciências humanas e na educação a tendência majoritária é pela pesquisa qualitativa, o Grupo considerou importante que um coletivo que discute Questões Metodológicas da Pesquisa em Educação Ambiental contribua para esclarecer essa dúvida junto à comunidade de pesquisadores. Assim, podemos sintetizar a discussão no sentido de concluir que os dados quantificáveis de uma pesquisa não são suficientes para defini-la como quantitativa, ou seja, não é porque há dados quantificáveis que uma pesquisa não pode ser qualitativa. A identificação da pesquisa quantitativa e da pesquisa qualitativa, segundo nossas discussões, emerge das finalidades do processo de investigação, nos questionamentos que trazem essas pesquisas, pois finalidades e questionamentos conduzem a pesquisar formas diferenciadas de coleta e de análise dos dados. Para além dessa afirmação, o Grupo não continuou essa discussão, mas como tais estudos estão crescendo no meio acadêmico educacional, fica aqui 
apontada a necessidade de olharmos para elas com maior atenção e cuidado.

\section{O Materialismo Histórico Dialético: método ou teoria?}

Um dos mais importantes temas de análise que tem aparecido no GDP de Pesquisa em Educação Ambiental e Questões Metodológicas nas últimas edições do EPEA é a relação entre metodologia e referenciais teóricos em nossas pesquisas. Já no artigo referente à edição do EPEA de 2013 (TOZONI-REIS; SOUZA, 2014), problematizamos essa necessidade e agora, neste texto, as próprias discussões no GDP em 2015 que indicaram a necessidade de trazer para análise o Método Materialista Histórico e Dialético.

Diferentemente do que vemos nos estudos, de modo mais usual, sobre metodologia de pesquisa, o Método Materialista Histórico Dialético é, ao mesmo tempo, método e teoria. Ou seja, é um Método (com M maiúsculo), porque é uma forma - metodológica - de interpretação da realidade, da realidade histórica e social. Mas não é uma forma neutra de interpretar a realidade, o que a rigor não existe, mas uma forma que faz uma crítica à realidade social e histórica do modo capitalista de produção. Portanto, é uma teoria, ou como nos sugere o próprio subtítulo de $O$ Capital, a obra mais significativa de Marx e Engels (1968), os formuladores do Método: teoria crítica da economia política. Ou seja, é um Método de interpretar a realidade da vida humana, levando-se em conta a formação histórica da organização das sociedades que, da modernidade até os nossos dias, se organiza sob o modo capitalista de produção.

Como Método/Teoria, nos aponta um caminho metodológico apresentado com clareza e objetividade por Saviani (2007). Na interpretação dos fenômenos sociais (e aqui incluímos o fenômeno educativo, assim como o fenômeno ambiental - educativo ambiental) é preciso partir do empírico (a realidade assim como se apresenta - realidade imediata) e, pelo movimento do pensamento (buscar as contradições, realizar abstrações, reflexões teóricas sobre a realidade), alcançar-se o concreto (a realidade totalmente compreendida, realidade pensada, concreto pensado).

Dessa forma, o Método Materialista Histórico Dialético como teoria e método, traz, segundo compreendemos, a possibilidade de articular radicalmente as questões metodológicas apontando um caminho de interpretação da realidade - com as questões epistemológicas posicionando-se criticamente frente a realidade histórica do modo capitalista de produção -, um dos pontos mais debatidos por este GDP em vários dos seus encontros e, talvez, a maior contribuição do GDP para a pesquisa em educação ambiental.

\section{Estudos do Estado da Arte são Metapesquisas?}

O questionamento sobre os estudos do tipo estado da arte, tão presentes nas últimas edições dos EPEAs, serem ou não metapesquisas, levou o Grupo a considerações iniciais sobre o que se configuraria como uma metapesquisa.

Carvalho (2016), ao situar o projeto interinstitucional de pesquisa que desenvolve sobre o estado da arte da pesquisa em EA no Brasil (CARVALHO et al., 2012), traz contribuições importantes para essa questão. Considerando o aumento significativo do número de trabalhos desenvolvidos na área de pesquisa em EA, o autor chama a atenção sobre vários autores e grupos de pesquisa que passaram a abordar o conjunto das investigações desta área, como o novo objeto de investigação da própria área de pesquisa. A esse tipo de pesquisa, cuja finalidade é a investigação sobre o próprio campo da pesquisa, Carvalho, apoiado em diversos autores, denominou de metapesquisa, entendida como uma pesquisa de natureza integrativa, ou seja, a qual se busca uma síntese integrativa da produção acadêmica em uma determinada área do conhecimento, em um período definido de tempo. Assim sendo, os estudos do tipo 
estado da arte podem ser entendidos, aqui, como metapesquisas, já que têm como foco central de sua investigação as pesquisas que vêm sendo produzidas em um determinado campo do conhecimento. Tais estudos do estado da arte, ou metapesquisas, permitem, ao mesmo tempo, estudos panorâmicos e de tendências e estudos mais aprofundados a partir de recortes temáticos.

\section{Considerações Finais}

Construímos este texto com o objetivo de divulgar, junto aos pesquisadores em educação ambiental, aquilo que os EPEAS, no espaço ocupado pelo GDP de Pesquisa em Educação Ambiental e Questões Metodológicas, vêm acumulando de discussões acerca desse tema tão relevante para os pesquisadores em geral e, mais ainda, para aqueles que se dedicam à pesquisa em educação ambiental, pois é fato que esse campo é constituído por pesquisadores que tem sua formação inicial em muitas e diversas áreas do conhecimento. Considerando que são também muitas e diversas suas dificuldades, assim como muitos e diversos os caminhos metodológicos trilhados, pudemos trazer aqui apenas algumas contribuições.

Nesse sentido, tomemos como finalização dessa contribuição a última das questões que discutimos em 2015 nesse GDP: Quais os principais problemas da discussão metodológica da pesquisa em EA a serem superados?

Entre tantos outros, sabemos que a descrição exaustiva de técnicas/instrumentos e de coleta de dados da pesquisa, sem uma discussão teórica e epistemológica, é um dos problemas metodológicos mais significativos que encontramos nas pesquisas em educação ambiental. Segundo nossas discussões, esse problema persiste nos trabalhos apresentados no EPEA 2015.

A Pesquisa Qualitativa, que sabemos hegemônica na pesquisa em educação como também na pesquisa em educação ambiental, tem sido pouco compreendida pelos pesquisadores da área, segundo nossas análises nos trabalhos apresentados nos EPEAs. Ela tem sido tratada quase que como um clichê, pois vários trabalhos reproduzem ipsilipter trechos de obras que tratam da abordagem qualitativa da pesquisa educacional sem nenhuma aproximação com o objeto de estudo em questão, em especial aos passos e procedimentos metodológicos utilizados na pesquisa apresentada.

Nas duas sessões do GDP Questões Metodológicas discutimos, também, como ainda persiste em alguns trabalhos de pesquisa em educação ambiental a confusão entre metodologia de pesquisa e metodologia de ensino/educacional/ação pedagógica. Ou seja, ao descrever a metodologia do estudo - exigência das normas de apresentação de trabalhos nos EPEAs alguns autores descrevem ações pedagógicas em educação ambiental, detalhando a metodologia educativa e não sua dimensão de pesquisa. Esta ainda parece ser uma dificuldade dos pesquisadores, - especialmente os jovens pesquisadores - que vem de áreas variadas e chegam na educação. Ainda, é preciso afirmar que a ação educativa ambiental em si não é pesquisa, embora possa se transformar num objeto de estudo, configurando-se, assim, num processo de pesquisa. Isto é, não é a ação pedagógica a pesquisa, mas a sua análise, o estudo investigativo da - ou das - ação em educação ambiental.

Além desses problemas, até aqui elencados nestas Considerações Finais, discutimos, principalmente, a ausência de um percurso metodológico que articule técnicas, instrumentos e análise dos dados com referenciais teórico-metodológicos. Consideramos essa ausência o mais significativo problema identificado na pesquisa em educação ambiental pelos membros participantes do G que estão DP nos EPEAs e que já foi problematizado por nós neste artigo.

Mas, além dos problemas que permanecem relacionados às questões metodológicas da pesquisa em educação ambiental, o Grupo identificou, também, alguns daqueles que, de certa maneira, já foram superados nos trabalhos apresentados nos EPEAs. 
Não ocorreu em nosso GDP, por exemplo, no VIII EPEA de 2015, a presença de pesquisadores em busca de um minicurso ou uma oficina de Metodologia de Pesquisa em EA, como apareceu em edições anteriores. Nesse ponto, parece que os participantes do evento têm compreendido melhor a natureza dos GDPs, pois tivemos participantes que vieram em busca de discussões metodológicas mais aprofundadas, trazendo questões de suas próprias pesquisas.

Um outro ponto que nos chamou a atenção foi o fato de que não tivemos mais no GDP participantes buscando receitas para definir, em seus trabalhos de pesquisa, a metodologia mais adequada, como apareceu em outras edições do EPEA. Avançamos na compreensão de que a Metodologia escolhida não se resume às técnicas e instrumentos de coleta de dados e sua consequente descrição nos trabalhos que divulgam as pesquisas. Considerando que a articulação teórica e epistemológica com a dos procedimentos metodológicos são importantes, os participantes do GDP, por mais uma vez, indicaram a necessidade deste Grupo buscar articulações com o GDP de Pesquisa em EA e Questões Epistemológicas.

Também fez parte da discussão um outro problema, considerado pelo Grupo como importante a ser enfrentado pela pesquisa em educação ambiental: a praticamente inexistente publicação de pesquisas que focam a questão metodológica, ou seja, a falta de trabalhos que tomem a questão metodológica dessas pesquisas como objeto de estudo, identificando que este campo pode ser explorado nas pesquisas em EA. Sabemos que a área da educação, onde se situa com especificidades - a educação ambiental, já produziu uma gama enorme de conhecimentos sobre metodologia de pesquisa em educação, mas consideramos importante que nossas publicações problematizem esses conhecimentos no campo da educação ambiental para atingir mais diretamente nossos pesquisadores, principalmente se considerarmos que a pesquisa em educação ambiental é realizada por um conjunto muito heterogêneo de pesquisadores no que diz respeito aos paradigmas da ciência, o que tem implicação direta na Metodologia, como estamos já discutindo neste artigo.

E, para finalizar, o GDP de Pesquisa em Educação Ambiental e Questões Metodológicas concluiu que a Metodologia de uma pesquisa não é dada, ou seja, não vem pronta a partir de revisões bibliográficas - indispensáveis, é claro - sobre esse assunto em análise, mas ela tem que ser construída pelo pesquisador antes, durante e após o próprio processo de investigação científica. Não podemos esquecer que o desenvolvimento de uma Metodologia envolve posicionamentos e escolhas variadas, caracterizando-o como processual, se constituindo ao longo da pesquisa, sendo pertinente lembrar, aqui, o canto do poeta sevilhano: "Caminante no hay caminho, se hace camino al andar".

\section{Referências:}

CARVALHO, L.M. et al. A educação ambiental no Brasil: análise da produção acadêmica - teses e dissertações. CNPq: Relatório Científico. Rio Claro, UNESP - Rio Claro, UNICAMP - Campinas, USP - Ribeirão Preto, 2012.

CARVALHO, L.M. Pesquisa em Educação Ambiental no Brasil: um campo em construção? 2015. p. Tese (Livre Docência) - Universidade Estadual Paulista, Rio Claro, 2015.

MARX, K.; ENGELS, F. O Capital: crítica da economia política. Rio de Janeiro: Civilização Brasileira, 1968.

SAVIANI, D. Do senso comum à consciência filosófica. Campinas: Autores Associados, 2007.

TOZONI-REIS, M.F.C.; SOUZA, D.C. Pesquisa em Educação Ambiental e Questões Metodológicas: uma discussão coletiva. Rev. Pesquisa em Educação Ambiental, Rio Claro, v. 9, n 1, p. 133-143, 2014. 
VENTURA, G.; FREIRE, L. A análise crítica do discurso como caminho teórico-metodológico na compreensão e no enfrentamento da questão ambiental. In: Encontro de Pesquisa em Educação Ambiental - EPEA, 8, 2015, Rio de Janeiro, Anais..., Rio de Janeiro, 2015, p. 1-14. 